\title{
Genetic associations with plasma B12, B6, and folate levels in an ischemic stroke population from the Vitamin Intervention for Stroke Prevention (VISP) trial
}

\section{Keith L. Keene ${ }^{1,2}$, Wei-Min Chen ${ }^{1,3}$, Fang Chen ${ }^{1}$, Stephen R. Williams ${ }^{1}$, Stacey D. Elkhatib ${ }^{1}$, Fang-Chi Hsu ${ }^{4}$, Josyf C. Mychaleckyj ${ }^{1,3}$, Kimberly F. Doheny, Elizabeth W. Pugh ${ }^{5}$, Hua Ling ${ }^{5}$, Cathy C. Laurie ${ }^{6}$, Stephanie M. Gogarten ${ }^{6}$, Ebony B. Madden ${ }^{7}$, Bradford B. Worrall ${ }^{3,8 *}$ and Michele M. Sale ${ }^{1,3,9}$ on behalf of the GARNET Collaborative Research Group}

${ }^{1}$ Center for Public Health Genomics, University of Virginia, Charlottesville, VA, USA

2 Department of Biology, Center for Health Disparities, East Carolina University, Greenville, NC, USA

${ }^{3}$ Department of Public Health Sciences, University of Virginia, Charlottesville, VA, USA

${ }^{4}$ Department of Biostatistical Sciences, Wake Forest School of Medicine, Winston Salem, NC, USA

${ }^{5}$ Center for Inherited Disease Research, Johns Hopkins University School of Medicine, Baltimore, MD, USA

${ }^{6}$ Department of Biostatistics, University of Washington, Seattle, WA, USA

${ }^{7}$ National Human Genome Research Institute, National Institutes of Health, Bethesda, MD, USA

${ }^{8}$ Department of Neurology, University of Virginia, Charlottesville, VA, USA

${ }^{9}$ Department of Biochemistry \& Molecular Genetics, University of Virginia, Charlottesville, VA, USA

\section{Edited by:}

Zhigang Li, Dartmouth College, USA

Reviewed by:

Konstantin G. Arbeev, Duke

University, USA

Raghib Ali, University of Oxford, UK Jinyoung Byun, Dartmouth College, USA

\section{*Correspondence:}

Bradford B. Worrall, Department of Neurology, University of Virginia Health System, Charlottesville, PO Box 800394, VA 22908, USA e-mail: bbw9r@virginia.edu
Background: B vitamins play an important role in homocysteine metabolism, with vitamin deficiencies resulting in increased levels of homocysteine and increased risk for stroke. We performed a genome-wide association study (GWAS) in 2,100 stroke patients from the Vitamin Intervention for Stroke Prevention (VISP) trial, a clinical trial designed to determine whether the daily intake of high-dose folic acid, vitamins $B_{6}$, and $B_{12}$ reduce recurrent cerebral infarction.

Methods: Extensive quality control (OC) measures resulted in a total of 737,081 SNPs for analysis. Genome-wide association analyses for baseline quantitative measures of folate, Vitamins $B_{12}$, and $B_{6}$ were completed using linear regression approaches, implemented in PLINK.

Results: Six associations met or exceeded genome-wide significance $\left(P \leq 5 \times 10^{-08}\right)$. For baseline Vitamin $B_{12}$, the strongest association was observed with a non-synonymous SNP (nsSNP) located in the CUBN gene $\left(P=1.76 \times 10^{-13}\right)$. Two additional CUBN intronic SNPs demonstrated strong associations with $B_{12}\left(P=2.92 \times 10^{-10}\right.$ and $\left.4.11 \times 10^{-10}\right)$, while a second nsSNP, located in the TCN1 gene, also reached genome-wide significance $\left(P=5.14 \times 10^{-11}\right)$. For baseline measures of Vitamin $\mathrm{B}_{6}$, we identified genome-wide significant associations for SNPs at the ALPL locus (rs1697421; $P=7.06 \times 10^{-10}$ and rs1780316; $P=2.25 \times 10^{-08}$ ). In addition to the six genome-wide significant associations, nine SNPs (two for Vitamin $B_{6}$, six for Vitamin $B_{12}$, and one for folate measures) provided suggestive evidence for association $\left(P \leq 10^{-07}\right)$.

Conclusion: Our GWAS study has identified six genome-wide significant associations, nine suggestive associations, and successfully replicated 5 of 16 SNPs previously reported to be associated with measures of B vitamins. The six genome-wide significant associations are located in gene regions that have shown previous associations with measures of $B$ vitamins; however, four of the nine suggestive associations represent novel finding and warrant further investigation in additional populations.

Keywords: VISP, association, GWAS, one-carbon metabolism, B12, B6, folate

\section{INTRODUCTION}

The B vitamins constitute a group of water-soluble vitamins that play an important role in human health and cellular functions including growth and development (1). Vitamins $\mathrm{B}_{6}$ (pyridioxine), $\mathrm{B}_{9}$ (folic acid or folate), and $\mathrm{B}_{12}$ (cobalamin) have garnered extensive attention for their putative impacts on human health and diseases, ranging from cardiovascular disease and stroke to neurocognitive function and depression. Specifically, these B vitamins are critical for the maintenance of red blood cells (2), components of the nervous (3), and immune systems (4). Vitamin $B_{6}$ 
deficiency, most common in the elderly, has been associated with conditions such as anemia, and neurological abnormalities such as depression, cognitive dysfunction, and neuropathy (5). Vitamin $\mathrm{B}_{12}$ deficiency can result in irreversible brain and nervous system damage and may be responsible for common symptoms such as fatigue and poor memory $(6,7)$. Folate (Vitamin $B_{9}$ ) is critical for fetal growth and brain development, therefore folate deficiencies during pregnancy can result in neural tube defects in babies (8). In addition, Vitamins $\mathrm{B}_{6}, \mathrm{~B}_{9}$, and $\mathrm{B}_{12}$ serve as important factors in homocysteine metabolism, with vitamin deficiencies resulting in increased levels of homocysteine $(9,10)$. Although controversial, elevated homocysteine levels are thought to increase risk for stroke (11) and vascular disease $(12,13)$.

Multiple factors contribute to variations in B vitamin levels in humans. A balanced diet is one approach to help minimize the detrimental effects of B vitamin deficiency. In January 1998, the United States Food and Drug Administration required manufacturers to fortify bread and grain products with folic acid to help prevent neural tube defects due to Vitamin $\mathrm{B}_{9}$ deficiency. These efforts have proven somewhat successful, with estimates from the 2002-2006 National Health and Nutrition Examination Survey (NHANES) reporting that most Americans are receiving adequate amounts of folate (14). In contrast, for Vitamin $\mathrm{B}_{12}$, data suggest that $5-15 \%$ of elderly patients are Vitamin $B_{12}$ deficient, including data from the Centers for Disease Control and Prevention (CDC) and the NHANES study (15-17). Poor dietary intake, malabsorption from food, and genetic predisposition may all cause vitamin deficiencies. Polymorphisms in genes involved in B vitamin metabolism and processing, transport, absorption, and excretion are logical candidate genes that can influence B vitamin levels. Two such examples include human conditions Imerslund-Grasbeck syndrome (IGS) and megaloblastic anemia-1. IGS, a rare autosomal recessive disorder caused by mutations in cubilin (CUBN) and/or amnionless $(A M N)$, was first characterized in the 1960s $(18,19)$ and results in megaloblastic anemia during childhood as a result of selective malabsorption of Vitamin $\mathrm{B}_{12}$. Additionally, genetic variants in the CUBN and $A M N$ genes are responsible for the Finnish and Norwegian types of megaloblastic anemia-1, respectively $(20,21)$.

Understanding the genetic factors contributing to vitamin deficiencies offers opportunities for screening and identification of high-risk individuals before the presentation of any clinical manifestations. To date, several large-scale genome-wide association studies (GWAS) testing for association with Vitamin $\mathrm{B}_{6}, \mathrm{~B}_{12}$, and folate have been published, resulting in more than 10 confirmed loci for these traits (22-25). Our group has conducted a GWAS for Vitamin $\mathrm{B}_{6}, \mathrm{~B}_{12}$, and folate in an effort both to identify novel associations and replicate previously reported associations for these traits in a population of ischemic stroke patients from the Vitamin Intervention for Stroke Prevention (VISP) clinical trial, an NIH-funded, multi-center, double-blind, randomized, controlled clinical trial designed to determine whether the daily intake of high-dose folic acid, Vitamins $\mathrm{B}_{6}$, and $\mathrm{B}_{12}$ reduced recurrent cerebral infarction and a combined vascular endpoint. Unlike the previous GWAS, the VISP study population represents an ethnically diverse population of older patients that present with elevated baseline homocysteine levels in the top quartile, have suffered a stroke, and thus, more closely represent the elderly population that is most prone to vitamin B deficiency and stroke.

\section{MATERIALS AND METHODS SUBJECTS}

The VISP trial was a multi-center, double-blind, randomized, and controlled clinical trial that enrolled patients aged 35 or older with homocysteine levels above the 25 th percentile at screening and a non-disabling cerebral infarction (NDCI) within 120 days of randomization $(26,27)$. NDCI was defined as an ischemic brain infarction not due to embolism from a cardiac source, characterized by the sudden onset of a neurological deficit. The deficit must have persisted for at least $24 \mathrm{~h}$, or if not, an infarction in the part of the brain corresponding to the symptoms must have been demonstrated by CT or MRI imaging. The trial was designed to determine if daily intake of a multivitamin tablet with highdose folic acid, vitamin $\mathrm{B}_{6}$, and vitamin $\mathrm{B}_{12}$ reduced recurrent cerebral infarction and non-fatal myocardial infarction (MI) or mortality. Subjects were randomly assigned to receive daily doses of the high-dose formulation $(n=1,827)$, containing $25 \mathrm{mg}$ pyridoxine $\left(\mathrm{B}_{6}\right), 0.4 \mathrm{mg}$ cobalamin $\left(\mathrm{B}_{12}\right)$, and $2.5 \mathrm{mg}$ folic acid; or the low-dose formulation $(n=1,853)$, containing $200 \mu \mathrm{g}$ pyridoxine, $6 \mu \mathrm{g}$ cobalamin, and $20 \mu \mathrm{g}$ folic acid. Enrollment in VISP began in August 1997, and was completed in December 2002, with 3,680 participants enrolled from 55 clinic sites across the U.S. and Canada and one site in Scotland. All human research was approved by the relevant institutional review boards (IRBs), and conducted according to the Declaration of Helsinki. The VISP study protocol was approved by the IRBs of Wake Forest School of Medicine (coordinating center) and the University of North Carolina at Chapel Hill School of Medicine (statistical center). The local IRB for each of the individual recruiting sites approved the VISP protocol and all participants provided written, informed consent. VISP data analysis by the Genomics and Randomized Trial Network (GARNET) was approved by University of Virginia School of Medicine IRB.

\section{GENOME-WIDE ASSOCIATION STUDY IN VISP}

A subset of VISP participants provided consent for inclusion in genetic studies. These participants were included in the GWAS component of VISP, supported by the National Human Genome Research Institute (NHGRI), Grant U01 HG005160, as part of the Genomics and Randomized Trials Network (GARNET); dbGaP Study Accession: phs000343.v3.p1. Samples were genotyped at the Johns Hopkins Center for Inherited Disease Research (CIDR), using the Illumina HumanOmni1-Quad_v1-0_B BeadChip (Illumina, San Diego, CA, USA). Individuals were excluded if they were unexpected duplicates or had gender discrepancies. A total of 2,100 individuals were included in the final genetic analyses; summary statistics are provided in Table 1. These subjects consisted of 1,725 individuals of European descent, 258 individuals of African descent, and 117 individuals classified as others.

\section{BIOMARKER MEASUREMENTS IN VISP}

As previously described (28), basal levels of folate and Vitamin $\mathrm{B}_{12}$ were determined by the central laboratory at Oregon Regional Primate Research Center using single radioassays of folate and Vitamin $B_{12}$ (Bio Rad Quantaphase II, Bio Rad Diagnostics, Hercules, 
Table 1 | Demographic summary statistics.

\begin{tabular}{lc}
\hline Number of individuals (EA/AA/other) & $2100(1725 / 258 / 117)$ \\
Age (years) & $67.2 \pm 10.8$ \\
Mean \pm SD & $35-89$ \\
Range & $37.4(785)$ \\
$\%$ Female participants (N) & 15.6 \\
Current smokers (\%) & 71.0 \\
Hypertension (\%) & 27.1 \\
Diabetes mellitus (\%) & \\
B Vitamin baseline measures & $42.45 \pm 37.38$ \\
Vitamin $\mathrm{B}_{6}(\mathrm{pm} / \mathrm{mL}) \pm \mathrm{SD}$ & 33.49 \\
Median & $358.79 \pm 181.91$ \\
Vitamin $\mathrm{B}_{12}(\mathrm{pg} / \mathrm{mL}) \pm \mathrm{SD}$ & 326 \\
Median & $25.86 \pm 15.91$ \\
Folate $(\mathrm{ng} / \mathrm{mL}) \pm \mathrm{SD}$ & 22.67 \\
Median &
\end{tabular}

CA, USA). For measures of Vitamin $\mathrm{B}_{6}$, EDTA plasma samples were analyzed using a commercially available method for plasma Pyridoxine 5' Phosphate (ALPCO Inc Windham, NH, USA). The principle of the assay is as follows: ${ }^{3} \mathrm{H}$-tyrosine is decarboxylated by the vitamin $\mathrm{B}_{6}$ dependent enzyme tyrosine apodecarboxlase to ${ }^{3} \mathrm{H}$-tyramine. The activity of tyrosine apodecarboxlase is quantitatively dependent on the amount of PLP present in the reaction mixture. The ${ }^{3} \mathrm{H}$-tyramine thus produced is selectively extracted into the scintillation cocktail and can be measured by liquid scintillation counting. The excess ${ }^{3} \mathrm{H}$-tyrosine remains in the aqueous phase and is not measured.

\section{STATISTICAL ANALYSES}

Extensive quality control (QC) measures were performed, resulting in a total of 737,081 SNPs for analysis. QC measures included filtering SNPs based on missing call rate, Mendelian errors in control trios, deviation from Hardy-Weinberg equilibrium in controls, discordant calls in duplicate samples, sex differences in allele frequency or heterozygosity, and minor allele frequency (MAF) (29). Briefly, samples were clustered and genotypes determined using GenomeStudio (version 2010.2). For initial QC, SNPs meeting one or more of the following criteria were excluded: call rate $<85 \%$, more than one replicate HapMap error, or cluster separation $<0.2$. Genotype calls for individual chromosomes in samples with large chromosomal anomalies $(>10 \mathrm{Mb})$ or missing call rate $>5 \%$ were filtered out. Furthermore, samples with overall missing call rates $>5 \%$ and SNPs with call rates $<95 \%$ and Hardy-Weinberg $P$-values $\leq 10^{-4}$ were excluded from subsequent analyses. Multidimensional Scaling (MDS), utilizing the software KING (30), was performed to address confounders due to population substructure. Genome-wide association analyses for baseline quantitative measures of folate, and Vitamins $\mathrm{B}_{12}$ and $\mathrm{B}_{6}$ were performed using linear regression approaches, assuming an additive model, as implemented in PLINK; using age, sex, and the top 10 principal components as covariates. Inverse normal transformation was performed for each of the quantitative traits, prior to analysis. Inverse normal transformations were used to maintain ranks of the trait for each individual and minimize the impact of outliers while also allowing for sufficient power. Regression coefficients (beta), coefficient T-statistic (STAT), and $P$-values (asymptotic $P$-value for $T$-statistic) were calculated for the tested (minor) allele. The proportion of total variance explained $\left(h^{2}\right)$ was calculated as $h^{2}=$ Beta $^{2} \times 2 \times$ MAF $\times(1-M A F)$. Our GWAS scan results showed no evidence for inflation (GC lambda $\leq 1.013$ in all scans.).

\section{RESULTS}

We identified six associations that meet or exceed genome-wide significance $\left(P \leq 5 \times 10^{-08}\right.$; Table 2; Figure S1 in Supplementary Material). Of these six associations, four were for Vitamin $\mathrm{B}_{12}$, while the remaining two were for Vitamin $\mathrm{B}_{6}$. The strongest evidence of association was observed for baseline Vitamin $\mathrm{B}_{12}$ $\left(P=1.76 \times 10^{-13}\right.$; beta $\left.=-0.22\right)$ with a non-synonymous SNP (nsSNP), located on chromosome 10 in the CUBN gene. Two additional CUBN intronic SNPs (Figure 1) were also strongly associated with Vitamin $\mathrm{B}_{12}\left(P=2.92 \times 10^{-10}\right.$; beta $=-0.19$ and $4.11 \times 10^{-10}$; beta $\left.=-0.18\right)$. A second nsSNP, located on chromosome 11 in the transcobalamin 1 (TCN1) gene (Figure 2), was also associated with baseline measures of Vitamin $\mathrm{B}_{12}$ $\left(P=5.14 \times 10^{-11}\right.$; beta $\left.=-0.29\right)$. The two genome-wide significant associations for Vitamin $\mathrm{B}_{6}$ measures (Figure 3 ) were located in the alkaline phosphatase (ALPL), liver/bone/kidney gene region ( $\mathrm{rs} 1697421 ; P=7.06 \times 10^{-10}$, beta $=0.173$ and $\mathrm{rs1780316}$; $P=2.25 \times 10^{-08} ;$ beta $\left.=-0.325\right)$. Although not reaching the genome-wide significance threshold, our GWAS study has identified nine additional SNPs with suggestive $\left(P \leq 10^{-07}\right)$ evidence of association, two for measures of Vitamin $\mathrm{B}_{6}$, six for measures of Vitamin $B_{12}$, and one for measures of folate (Table 2 ). A cluster of suggestive associations for Vitamin $B_{12}$ was observed on chromosome 19, near the fucosyltransferase 2 (FUT2) gene. PValues for the four associated SNPs ranged from $9.33 \times 10^{-07}$ to $2.67 \times 10^{-07}$. Individually, each associated SNP explains only a small amount of the variance $\left(h^{2}\right)$ for each trait (ranging from 0.009 to 0.021 ).

In addition to our genome-wide analyses, we performed a lookup of 16 SNPs previously associated with measures of vitamin $\mathrm{B}_{6}$ $(n=1)(22)$, vitamin $\mathrm{B}_{12}(n=12)(22-24,31)$, and folate $(n=3)$ $(22,23,25)$. Of the 16 SNPs previously reported in the literature, genotype data were available for 10 of the reported SNPs, while surrogate SNPs in high linkage disequilibrium (LD) $\left(r^{2}>0.9\right)$ or the most significant SNP within $100 \mathrm{~kb}$ of the reported SNP were reported for the remaining six SNPs. Accounting for multiple testing $(P=0.05 / 16)$, five of the 16 SNPs, located in $A L P L, M S 4 A 3$, TCN1, CUBN, and FUT2, were successfully replicated $(P \leq 0.003)$ in our study (Table 3; Table S1 in Supplementary Material). For comparison, association results for the untransformed B vitamin measures are reported in Table S2 in Supplementary Material.

\section{DISCUSSION}

We performed a GWAS for measures of Vitamin $B_{12}$, Vitamin $\mathrm{B}_{6}$, and folate by evaluating 737,081 SNPs in 2,100 participants from the Vitamin Intervention for Stroke Prevention (VISP) clinical trial. We observed six associations that reached genome-wide significance $\left(P \leq 10^{-08}\right)$, an additional nine SNPs with suggestive $\left(P \leq 10^{-07}\right)$ evidence of association, while replicating five 
Table 2 | Association results for SNPs with genome-wide $\left(P \leq 5 \times 10^{-08}\right)$ significance or suggestive evidence $\left(P \leq 10^{-07}\right)$ for association.

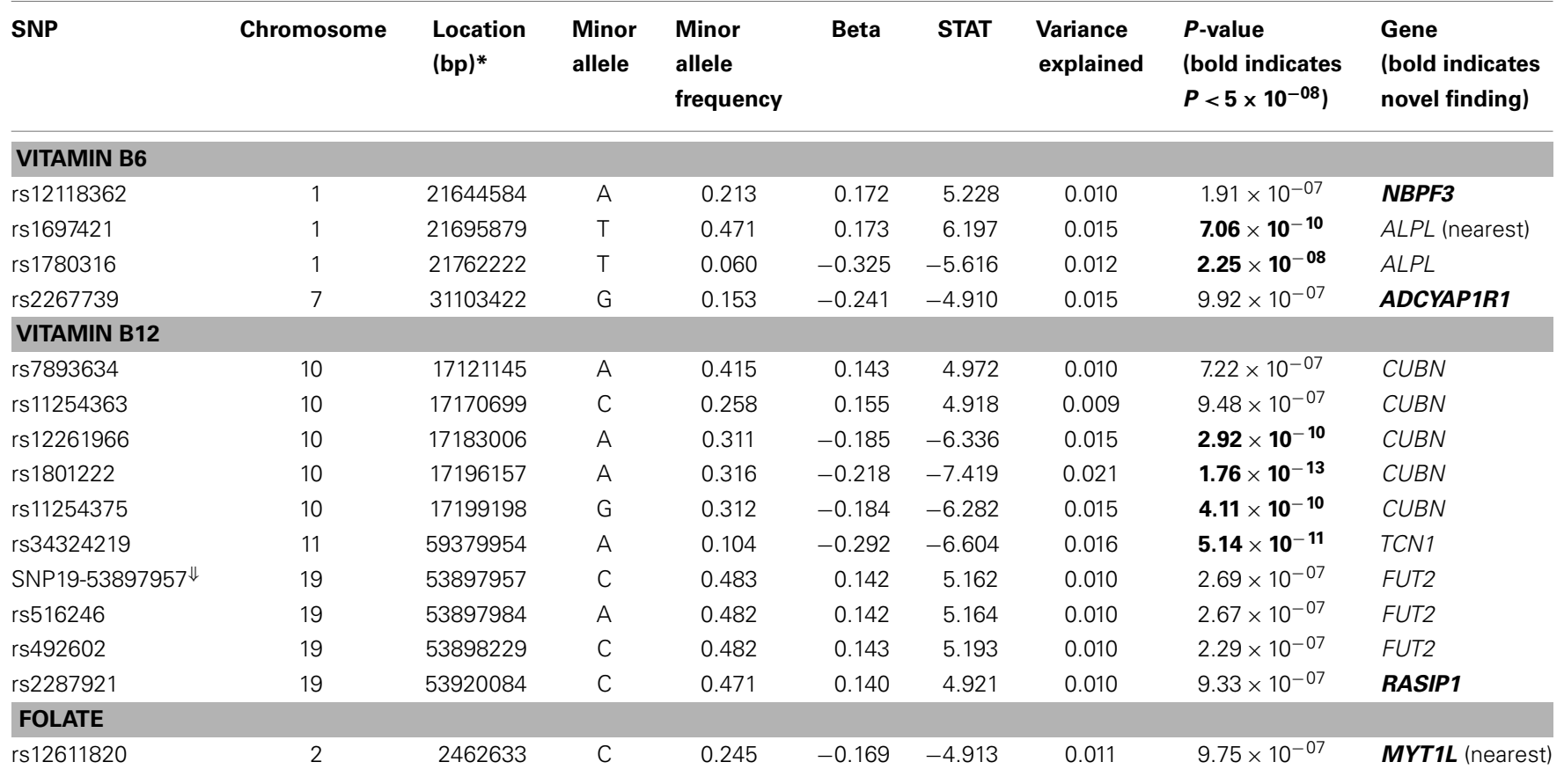

* Based on hg18

${ }^{*}$ Corresponds to SNP rs516316

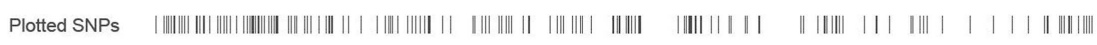

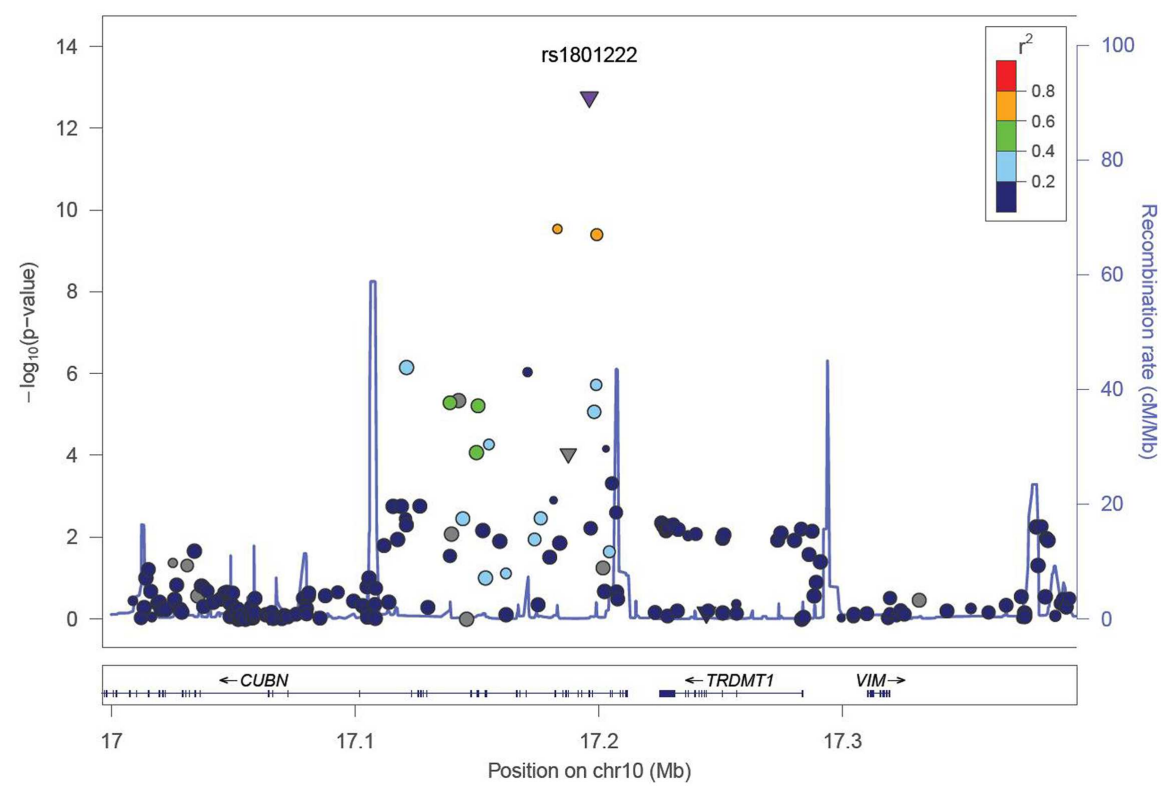

FIGURE 1 | LocusZoom (49) association plot for single SNP associations with Vitamin $\mathbf{B}_{12}$ at the CUBN locus. The SNP position and -LOG ( $P$-value) are plotted on the $X$ and $Y$ axis, respectively.

previously reported SNP associations. The most convincing associations were observed for measures of Vitamin B12 at the CUBN and TCN1 loci and the ALPL locus for measures of Vitamin B6.
Although we did not observe any genome-wide significant associations for folate, we did detect suggestive evidence for association $\left(P=9.75 \times 10^{-07}\right)$ near the MYT1L gene, located on chromosome 

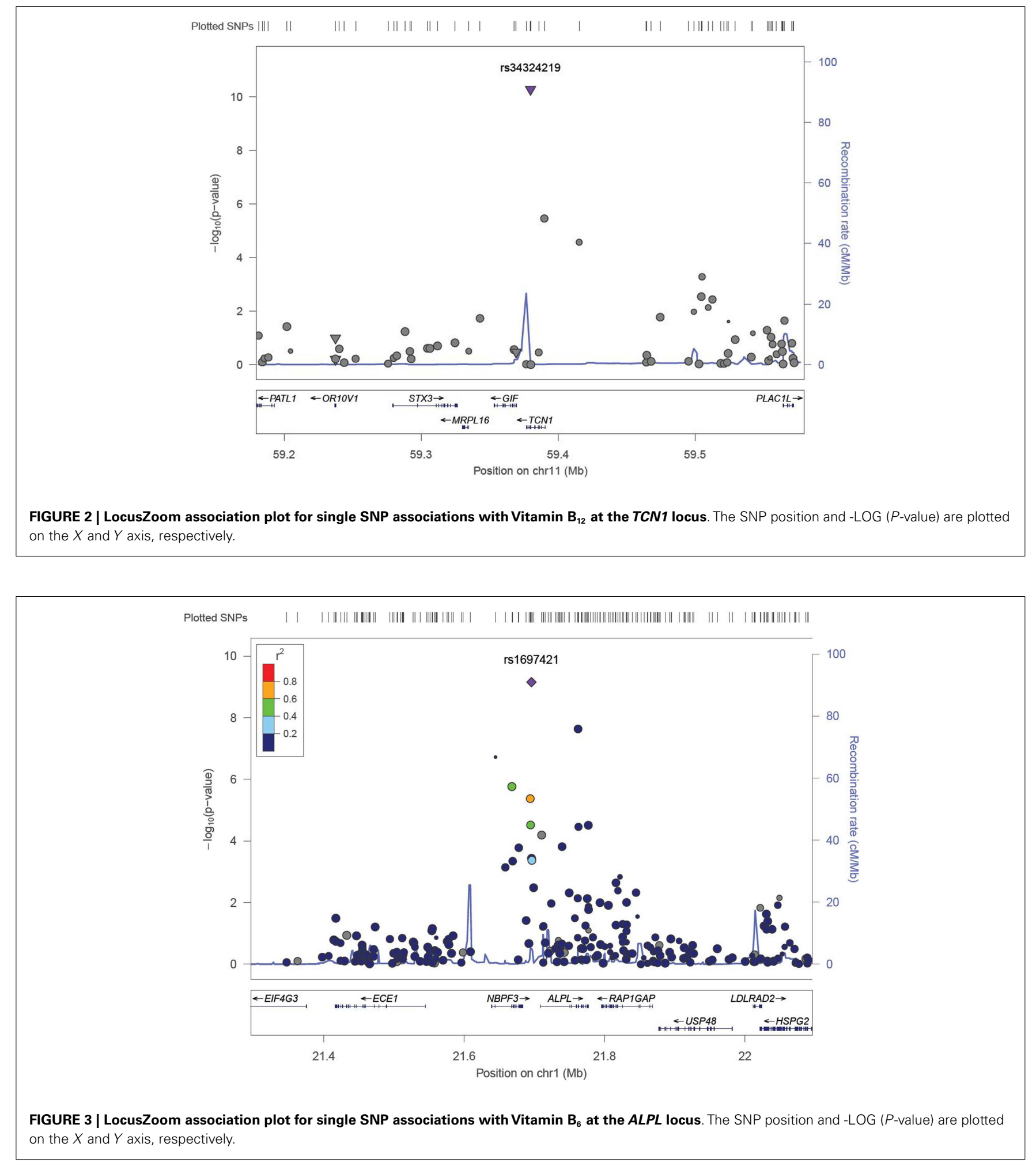

2. Interestingly, genetic variations at this locus have been associated with depression (32) and schizophrenia (33-35). This locus may help explain the recent data positively correlating serum folate levels with cognitive test scores in children (36); suggesting further evaluation of the effects of folate levels in the elderly are warranted.
The most robust associations for Vitamin $\mathrm{B}_{12}$ levels were observed at the CUBN, FUT2, and TCN1 loci (Table 2). A cluster of five SNPs spanning the CUBN gene provided evidence for association with Vitamin $B_{12}$ measures ( $P$-values ranging from $9.48 \times 10^{-07}$ to $\left.1.75 \times 10^{-13}\right)$. The most significantly associated 
Table 3 | Significant associations of 16 previously reported associations of Vitamin $B_{6}$, Vitamin $B_{12}$, and folate.

\begin{tabular}{|c|c|c|c|c|c|c|}
\hline SNP & Chromosome & Gene & Literature $\boldsymbol{P}$-value & Reference & Surrogate SNP & VISP $P$-value \\
\hline \multicolumn{7}{|c|}{ VITAMIN B6 } \\
\hline rs1256335 & 1 & $A L P L$ & $1.40 \times 10^{-15}$ & (22) & - & $3.41 \times 10^{-05}$ \\
\hline rs1801222 & 10 & CUBN & $2.87 \times 10^{-09}$ & (22) & - & $1.76 \times 10^{-13}$ \\
\hline rs526934 & 11 & TCN1 & $2.25 \times 10^{-10}$ & (22) & - & $3.38 \times 10^{-06}$ \\
\hline
\end{tabular}

SNP in this region, rs1801222, was a non-synonymous variant resulting in a missense mutation, Phenylalanine to Serine. These results were not surprising considering rs1801222 was previously associated with Vitamin $B_{12}$ measures (22) and the protein expressed by CUBN forms a receptor complex responsible for Vitamin $B_{12}$ internalization in the ileum (37). Furthermore, genetic variants in $C U B N$ are responsible for the Finnish type of megaloblastic anemia-1 (38) in humans and more broadly for IGS in canines as well $(39,40)$. A second cluster of suggestive associations near FUT2 gene were consistent with previously reported associations in this region $(24,25,41)$.

A second missense mutation (rs34324219), located in the Vitamin $\mathrm{B}_{12}$ binding protein, TCN1 gene was associated with baseline measures of Vitamin $\mathrm{B}_{12}\left(P=5.148 \times 10^{-11}\right)$. The nsSNP, rs34324219, results in an Aspartic acid to Tyrosine substitution and represents the second most significant association in our study. In the same VISP population, our group previously detected associations between genetic variants of the related gene, TCN2, and recurrent stroke risk (42). Although TCN1 is a logical candidate gene influencing Vitamin $B_{12}$ measures in this region, associations with variants in the nearby $(\sim 200 \mathrm{~kb})$ MS4A3 gene (24) suggest that multiple genes in this region may impact Vitamin $\mathrm{B}_{12}$ levels. In an attempt to replicate the associations observed in MS4A3 by Lin et al. (24) (rs2298585), we detected modest evidence of association for the surrogate SNP, rs7929589 $\left(r^{2}=0.39\right.$; $P=8.67 \times 10^{-04}$; Table 3 ). The protein encoded by MS4A3 has been proposed to function as a hematopoietic cell cycle regulator (43), another potential link to the anemia observed in individuals with Vitamin $B_{12}$ deficiency (44).

For measures of Vitamin $\mathrm{B}_{6}$, associations at the ALPL locus were most robust. Two variants at this locus reached genomewide significance (rs1697421; $P=7.06 \times 10^{-10}$ and rs1780316; $\left.P=2.25 \times 10^{-08}\right)$. GWAS associations for variants near $A L P L$ have been reported for Vitamin $B_{6}(22)$. In addition, this region also harbors GWAS associations with traits ranging from $\mathrm{TNF} \alpha$ response in patients with rheumatoid arthritis (45) to hematologic traits (46). While the physiological function of ALPLs are unknown, and no direct correlations have been made between $A L P L$ variants and cognitive function, tissue non-specific ALPL is increased in Alzheimer's disease patients (47). Furthermore, Alzheimer's disease patients have an increased risk of suffering a stroke (48).

The data were collected as part of a randomized clinical trial is a systematic and standardized fashion, which is a major strength of the study. VISP used centralized laboratory analysis on all samples that complied with strict quality standards. The study population all had ischemic stroke and had elevated measures of serum homocysteine, which might limit generalizability. However, we replicated a substantial proportion of the previously identified genetic variants from studies using a more "general population." All participants in the VISP clinical trial were 35 years of age or older and suffered a stroke within 120 days of enrollment. This study population also represents an older group of individuals (mean age 67.2 years) that is most prone to vitamin deficiency and subsequent public health concerns including dementia and stroke. We are unable to make any comparisons in normal, healthy individuals, or assess the relation of such associations on stroke risk and other vascular disorders; however, collectively, our finding may provide some insight into the genetic factors influencing measures of B vitamins, in a vulnerable population. Although some dietary measures were collected as part of the VISP trial, we were not able to incorporate dietary "exposure" as a covariate in our analyses. Thus, we cannot identify gene by environmental interactions.

In summary, we performed a GWAS for measures of Vitamin $\mathrm{B}_{6}, \mathrm{~B}_{12}$, and folate observing six genome-wide significant associations, nine suggestive associations, and successfully replicating 5 of 16 SNPs previously reported in the literature. Our study is the first of its kind evaluating genetic contributors for measurements of B vitamins in a stroke population. Additionally, this knowledge could lead to genetic screening approaches, which could identify pre-symptomatic individuals that could benefit from interventions such as enhanced vitamin supplementation prior to clinical manifestations.

\section{AUTHORS CONTRIBUTION}

Keith L. Keene - performed locus specific analyses, drafted manuscript, and constructed primary tables and figures. Wei-Min Chen - lead VISP statistical analyst, reviewed and edited manuscript. Fang Chen - performed initial GWAS analyses under the supervision of Wei-Min Chen. Stephen R. Williams - assisted with figures and summary statistics, reviewed and edited manuscript. Stacey D. Elkhatib - conducted initial review of literature for GWAS of B vitamin phenotypes, ran analyses of several candidates prior to GWAS data, reviewed and edited manuscript. Fang-Chi $\mathrm{Hsu}$ - contributed to the overall GWAS design and the writing of the manuscript. Josyf C. Mychaleckyj - assisted with statistical analyses, reviewed and edited manuscript. Kimberly F. Doheny generation of GWAS data and QC of GWAS data, reviewed and edited manuscript. Elizabeth W. Pugh - generation of GWAS data and QC of GWAS data, reviewed and edited manuscript. Hua 
Ling - generation of GWAS data and QC of GWAS data, reviewed and edited manuscript. Cathy C. Laurie - quality control of the VISP dataset, assisted with statistical analysis, reviewed and edited manuscript. Stephanie M. Gogarten - quality control of the VISP dataset, reviewed and edited manuscript. Ebony B. Madden Program Director for the project and made contributions to the writing of the manuscript. Bradford B. Worrall - Co-Principal investigator on GARNET, contributed to the design and analysis plan for paper, and made contributions to the writing of the manuscript. Michele M. Sale - Co-Principal investigator on GARNET, contributed to the design and analysis plan for paper, and made contributions to the writing of the manuscript.

\section{ACKNOWLEDGMENTS}

Study recruitment and collection of datasets for the VISP clinical trial were supported by an investigator-initiated research grant (R01 NS34447; PI James Toole) from the National Institute of Neurological Disorders and Stroke. GWAS genotyping was provided by the Center for Inherited Disease Research (U01 HG0044381; PI David Valle). Assistance with genetic data cleaning was provided by the GARNET Coordinating Center (U01 HG005157; PI Bruce S. Weir).

\section{SUPPLEMENTARY MATERIAL}

The Supplementary Material for this article can be found online at http://www.frontiersin.org/Journal/10.3389/fpubh.2014. 00112/abstract

\section{REFERENCES}

1. Al-Tahan J, Gonzalez-Gross M, Pietrzik K. B-vitamin status and intake in European adolescents. A review of the literature. Nutr Hosp (2006) 21(4):452-65.

2. Koury MJ, Ponka P. New insights into erythropoiesis: the roles of folate, vitamin B12, and iron. Annu Rev Nutr (2004) 24:105-31. doi:10.1146/annurev.nutr.24. 012003.132306

3. Kirsch SH, Hermann W, Obeid R. Genetic defects in folate and cobalamin pathways affecting the brain. Clin Chem Lab Med (2013) 51(1):139-55. doi:10.1515/ cclm-2012-0673

4. Webb AL, Villamor E. Update: effects of antioxidant and non-antioxidant vitamin supplementation on immune function. Nutr Rev (2007) 65(5):181-217. doi:10.1111/j.1753-4887.2007.tb00298.x

5. Spinneker A, Sola R, Lemmen V, Castillo MJ, Pietrzik K, Gonzalez-Gross M. Vitamin B6 status, deficiency and its consequences - an overview. Nutr Hosp (2007) 22(1):7-24.

6. Stabler SP. Clinical practice. Vitamin B12 deficiency. N Engl J Med (2013) 368(2):149-60. doi:10.1056/NEJMcp1113996

7. Yetley EA, Pfeiffer CM, Phinney KW, Bailey RL, Blackmore S, Bock JL, et al. Biomarkers of vitamin B-12 status in NHANES: a roundtable summary. Am J Clin Nutr (2011) 94(1):313S-21S. doi:10.3945/ajcn.111.013243

8. Reynolds EH. The neurology of folic acid deficiency. Handb Clin Neurol (2014) 120:927-43. doi:10.1016/B978-0-7020-4087-0.00061-9

9. Stover PJ. Polymorphisms in 1-carbon metabolism, epigenetics and folaterelated pathologies. J Nutrigenet Nutrigenomics (2011) 4(5):293-305. doi:10. $1159 / 000334586$

10. Selhub J, Jacques PF, Wilson PW, Rush D, Rosenberg IH. Vitamin status and intake as primary determinants of homocysteinemia in an elderly population. JAMA (1993) 270:2693-8. doi:10.1001/jama.270.22.2693

11. Wald DS, Law M, Morris JK. Homocysteine and cardiovascular disease: Evidence on causality from a meta-analysis. BMJ (2002) 325(7374):1202. doi:10. 1136/bmj.325.7374.1202

12. Ntaios GC, Savopoulos CG, Chatzinikolaou AC, Kaiafa GD, Hatzitolios A. Vitamins and stroke: the homocysteine hypothesis still in doubt. Neurologist (2008) 14(1):2-4. doi:10.1097/01.nrl.0000253066.85963.aa
13. Homocysteine Lowering Trialists' Collaboration. Lowering blood homocysteine with folic acid based supplements: meta-analysis of randomised trials. BMJ (1998) 316:894-8. doi:10.1136/bmj.316.7135.894

14. McDowell MA, Lacher DA, Pfeiffer CM, Mulinare J, Picciano MF, Radar JI, et al. Blood Folate Levels: The Latest NHANES Results. NCHS Data Brief (2008) 6:1-8.

15. Rajan S, Wallace JI, Beresford SA, Brodkin KI, Allen RA, Stabler SP. Screening for cobalamin deficiency in geriatric outpatients: prevalence and influence of synthetic cobalamin intake. J Am Geriatr Soc (2002) 50(4):624-30. doi:10.1046/j.1532-5415.2002.50155.x

16. Pennypacker LC, Allen RH, Kelly JP, Matthews LM, Grigsby J, Kaye K, et al. High prevalence of cobalamin deficiency in elderly outpatients. J Am Geriatr Soc (1992) 40(12):1197-204.

17. Matchar DB, McCrory DC, Millington DS, Feussner JR. Performance of the serum cobalamin assay for diagnosis of cobalamin deficiency. Am J Med Sci (1994) 308(5):276-83. doi:10.1097/00000441-199411000-00004

18. Imerslund O. Idiopathic chronic megaloblastic anemia in children. Acta Paediatr Suppl (1960) 49(Suppl 119):1-115. doi:10.1111/j.1651-2227.1960.tb07724.x

19. Grasbeck R. Familiar selective vitamin B12 malabsorption with proteinuria. A pernicious anemia-like syndrome. Nord Med (1960) 63:322-3.

20. Aminoff M, Tahvanainen E, Grasbeck R, Weissenbach J, Broch H, de la Chapelle A. Selective intestinal malabsorption of vitamin B12 displays recessive mendelian inheritance: assignment of a locus to chromosome 10 by linkage. Am J Hum Genet (1995) 57(4):824-31.

21. Tanner SM, Aminoff M, Wright FA, Liyanarachchi S, Kuronen M, Saarinen A, et al. Amnionless, essential for mouse gastrulation, is mutated in recessive hereditary megaloblastic anemia. Nat Genet (2003) 33(3):426-9. doi:10.1038/ng1098

22. Hazra A, Kraft P, Lazarus R, Chen C, Chanock SJ, Jacques P, et al. Genome-wide significant predictors of metabolites in the one-carbon metabolism pathway. Hum Mol Genet (2009) 18(23):4677-87. doi:10.1093/hmg/ddp428

23. Grarup N, Sulem P, Sandholt CH, Thorleifsson G, Ahluwalia TS, Steinthorsdottir V, et al. Genetic architecture of vitamin B12 and folate levels uncovered applying deeply sequenced large datasets. PLoS Genet (2013) 9(6):e1003530. doi:10.1371/journal.pgen.1003530

24. Lin X, Lu D, Gao Y, Tao S, Yang X, Feng J, et al. Genome-wide association study identifies novel loci associated with serum level of vitamin B12 in Chinese men. Hum Mol Genet (2012) 21(11):2610-7. doi:10.1093/hmg/dds062

25. Tanaka T, Scheet P, Giusti B, Bandinelli S, Piras MG, Usala G, et al. Genome-wide association study of vitamin B6, vitamin B12, folate, and homocysteine blood concentrations. Am J Hum Genet (2009) 84(4):477-82. doi:10.1016/j.ajhg.2009. 02.011

26. Spence JD, Howard VJ, Chambless LE, Malinow MR, Pettigrew LC, Stampfer $\mathrm{M}$, et al. Vitamin Intervention for Stroke Prevention (VISP) trial: rationale and design. Neuroepidemiology (2001) 20(1):16-25. doi:10.1159/000054753

27. Toole JF. Vitamin intervention for stroke prevention. J Neurol Sci (2002) 20(3204):121-4. doi:10.1016/S0022-510X(02)00265-4

28. Toole JF, Malinow MR, Chambless LE, Spence JD, Pettigrew LC, Howard VJ, et al. Lowering homocysteine in patients with ischemic stroke to prevent recurrent stroke, myocardial infarction, and death the vitamin intervention for stroke prevention (VISP) randomized controlled trial. JAMA (2004) 291:565-75. doi:10.1001/jama.291.5.565

29. Laurie CC, Doheny KF, Mirel DB, Pugh EW, Bierut LJ, Bhangale T, et al. . Quality control and quality assurance in genotypic data for genome-wide association studies. Genet Epidemiol (2010) 34:591-602. doi:10.1002/gepi.20516

30. Manichaikul A, Mychaleckyj JC, Rich SS, Daly K, Sale M, Chen WM. Robust relationship inference in genome-wide association studies. Bioinformatics (2010) 26(22):2867-73. doi:10.1093/bioinformatics/btq559

31. Stone N, Pangilinan F, Molloy AM, Shane B, Scott JM, Ueland PM, et al. Bioinformatic and genetic association analysis of microRNA target sites in one-carbon metabolism genes. PLoS One (2011) 6(7):e21851. doi:10.1371/journal.pone. 0021851

32. Wang T, Zeng Z, Li T, Liu J, Li J, Li Y, et al. Common SNPs in myelin transcription factor 1-like (MYT1L): association with major depressive disorder in the Chinese Han population. PLoS One (2010) 5(10):e13662. doi:10.1371/journal. pone. 0013662

33. Van Den Bossche MJ, Strazisar M, Cammaerts S, Liekens AM, Vandeweyer G, Depreeuw V, et al. Identification of rare copy number variants in high burden schizophrenia families. Am J Med Genet B Neuropsychiatr Genet (2013) 162B(3):273-82. doi:10.1002/ajmg.b.32146 
34. Lee Y, Mattai A, Long R, Rapoport JL, Gogtay N, Addington AM. Microduplications disrupting the MYT1L gene (2p25.3) are associated with schizophrenia. Psychiatr Genet (2012) 22(4):206-9. doi:10.1097/YPG.0b013e328353ae3d

35. Li W, Wang X, Zhao J, Lin J, Song XQ, Yang Y, et al. Association study of myelin transcription factor 1-like polymorphisms with schizophrenia in Han Chinese population. Gene Brain Behav (2012) 11(1):87-93. doi:10.1111/j.1601-183X. 2011.00734.x

36. Nguyen CT, Gracely EJ, Lee BK. Serum folate but not vitamin B-12 concentrations are positively associated with cognitive test scores in children aged 6-16 years. J Nutr (2013) 143(4):500-4. doi:10.3945/jn.112.166165

37. Kristiansen M, Kozyraki R, Jacobsen C, Nexo E, Verroust PJ, Moestrup SK. Molecular dissection of the intrinsic factor-vitamin B12 receptor, cubilin, discloses regions important for membrane association and ligand binding. J. Biol. Chem (1999) 274:20540-4. doi:10.1074/jbc.274.29.20540

38. Aminoff M, Carter JE, Chadwick RB, Johnson C, Gräsbeck R, Abdelaal MA, et al. Mutations in CUBN, encoding the intrinsic factor-vitamin B12 receptor, cubilin, cause hereditary megaloblastic anaemia 1. Nat Gene (1999) 21(3):309-13. doi:10.1038/6831

39. Owczarek-Lipska M, Jagannathan V, Drögemüller C, Lutz S, Glanemann B, Leeb $\mathrm{T}$, et al. A frameshift mutation in the cubilin gene (CUBN) in Border Collies with Imerslund-Gräsbeck syndrome (selective cobalamin malabsorption). PLoS One (2013) 8(4):e61144. doi:10.1371/journal.pone.0061144

40. Fyfe JC, Hemker SL, Venta PJ, Fitzgerald CA, Outerbridge CA, Myers SL, et al. An exon 53 frameshift mutation in CUBN abrogates cubam function and causes Imerslund-Gräsbeck syndrome in dogs. Mol Genet Metab (2013) 109(4):390-6. doi:10.1016/j.ymgme.2013.05.006

41. Hazra A, Kraft P, Selhub J, Giovannucci EL, Thomas G, Hoover RN, et al. Common variants of FUT2 are associated with plasma vitamin B12 levels. Nat Genet (2008) 40(10):1160-2. doi:10.1038/ng.210

42. Hsu FC, Sides EG, Mychaleckyj JC, Worrall BB, Elias GA, Liu Y, et al. Transcobalamin 2 variant associated with poststroke homocysteine modifies recurrent stroke risk. Neurology (2011) 77(16):1543-50. doi:10.1212/WNL. 0b013e318233b1f9

43. Donato JL, Ko J, Kutok JL, Cheng T, Shirakawa T, Mao XQ, et al. Human HTm4 is a hematopoietic cell cycle regulator. J Clin Invest (2002) 109(1):51-8. doi:10.1172/JCI200214025

44. Toprak B, Yalcin HZ, Colak A. Vitamin B12 and folate deficiency: should we use different cutoff value for hematologic disorders? Int J Lab Hematol (2014) 36(4):409-14. doi:10.1111/ijlh.12158
45. Krintel SB, Palermo G, Johansen JS, Germer S, Essioux L, Benayed R, et al. Investigation of single nucleotide polymorphisms and biological pathways associated with response to TNF $\alpha$ inhibitors in patients with rheumatoid arthritis. Pharmacogenet Genomics (2012) 22(8):577-89. doi:10.1097/FPC.0b013e3283544043

46. Kamatani Y, Matsuda K, Okada Y, Kubo M, Hosono N, Daigo Y, et al. Genomewide association study of hematological and biochemical traits in a Japanese population. Nat Genet (2010) 42(3):210-5. doi:10.1038/ng.531

47. Vardy ER, Kellett KA, Cocklin SL, Hooper NM. Alkaline phosphatase is increased in both brain and plasma in Alzheimer's disease. Neurodegener Dis (2012) 9(1):31-7. doi:10.1159/000329722

48. Wang HK, Tsai KJ, Huang CY, Wang LC, Lu K, Chen HJ, et al. Newly diagnosed dementia and increased risk of hemorrhagic stroke: A nationwide population-based study. Curr Alzheimer Res (2014) 11(3):291-8. doi:10.2174/ 1567205011666140131120351

49. Pruim RJ, Welch RP, Sanna S, Teslovich TM, Chines PS, Gliedt TP, et al. LocusZoom: Regional visualization of genome-wide association scan results. Bioinformatics (2010) 26(18):2336.2337. doi:10.1093/bioinformatics/btq419

Conflict of Interest Statement: The authors declare that the research was conducted in the absence of any commercial or financial relationships that could be construed as a potential conflict of interest.

Received: 12 May 2014; accepted: 21 July 2014; published online: 06 August 2014. Citation: Keene KL, Chen W-M, Chen F, Williams SR, Elkhatib SD, Hsu F-C, Mychaleckyj JC, Doheny KF, Pugh EW, Ling H, Laurie CC, Gogarten SM, Madden EB, Worrall BB and Sale MM on behalf of the GARNET Collaborative Research Group (2014) Genetic associations with plasma B12, B6, and folate levels in an ischemic stroke population from the Vitamin Intervention for Stroke Prevention (VISP) trial. Front. Public Health 2:112. doi: 10.3389/fpubh.2014.00112

This article was submitted to Epidemiology, a section of the journal Frontiers in Public Health.

Copyright (c) 2014 Keene, Chen, Chen, Williams, Elkhatib, Hsu, Mychaleckyj, Doheny, Pugh, Ling, Laurie, Gogarten, Madden, Worrall and Sale on behalf of the GARNET Collaborative Research Group. This is an open-access article distributed under the terms of the Creative Commons Attribution License (CC BY). The use, distribution or reproduction in other forums is permitted, provided the original author(s) or licensor are credited and that the original publication in this journal is cited, in accordance with accepted academic practice. No use, distribution or reproduction is permitted which does not comply with these terms. 